\title{
An Analysis of Factors Affecting Flowslide Deposit Morphology Using Taguchi Method
}

\author{
Zhao Duan, ${ }^{1,2}$ Yan-Bin Wu $\mathbb{D}^{1,2}$ Hao Tang, ${ }^{1,2}$ Jian-Quan Ma $\mathbb{D}^{1,2}$ and Xing-Hua Zhu ${ }^{3}$ \\ ${ }^{1}$ College of Geology and Environment, Xi'an University of Science and Technology, Xi'an 710054, China \\ ${ }^{2}$ Shaanxi Provincial Key Laboratory of Geological Support for Coal Green Exploitation, Xi'an 710055, China \\ ${ }^{3}$ College of Geological Engineering and Geomatics, Chang'an University, Xi'an 710064, China
}

Correspondence should be addressed to Yan-Bin Wu; 19209071021@stu.xust.edu.cn

Received 27 May 2020; Revised 28 June 2020; Accepted 7 July 2020; Published 27 August 2020

Academic Editor: Haiyun Shi

Copyright (C) 2020 Zhao Duan et al. This is an open access article distributed under the Creative Commons Attribution License, which permits unrestricted use, distribution, and reproduction in any medium, provided the original work is properly cited.

\begin{abstract}
Flowslides, as one type of landslides, are becoming a research hotspot due to their high speed and long runout distance, which can cause tremendous damage and economic loss. The scale of damage and deposit morphology of flowslide is closely related to factors like deposit volume, slope height, and slope angle. In order to assess the influence of these factors, a sandbox apparatus is developed, and the Taguchi method is used to design an experimental scheme to analyze the results of factors affecting the deposit morphology of flowslide. The results show that the factor that has the greatest impact on flowslide deposit morphology is slope angle, followed by the influence of volume and slope height. As slope angle increases, the maximum width, maximum length, area, and length-width ratio of the deposit first increase and then decrease. In addition, there should be a critical angle in the changes of deposit morphology that is between $60^{\circ}$ and $70^{\circ}$ under the experimental conditions. When the volume is $5.4 \times 10^{-3} \mathrm{~m}^{3}$, the slope angle is $70^{\circ}$, the slope height is $0.90 \mathrm{~m}$, and the changes of deposit morphology of the flowslide are the largest. In this study, considering the slope angle as a single variable, there is a single upheaval for a slope angle of $40^{\circ}$ and $50^{\circ}$ and a double upheaval at $60^{\circ}$ and $70^{\circ}$. The formation mechanism of the upheaval is analyzed based on the Mohr-Coulomb criterion and considered properties of the material. The apparent friction coefficient of a flowslide is spatially and lithologically different and increases nonlinearly as the slope angle increases. The initial benchmark of the slope angle and apparent friction coefficient curve are affected by the friction coefficient of the material; the position of the inflection point at which the curve increases rapidly is affected by the coefficient of velocity restitution.
\end{abstract}

\section{Introduction}

Landslides including slide and flowslide are often seen in the Loess Plateau of northwest China since the loess features metastable microstructure, high porosity, and water sensitivity. The hazards associated with flowslides are often closely related to volume, slope angle, slope height, and so on, because these conditions significantly affect a flowslide's moving distance [1-4]. Flowslides are becoming a research hotspot recently since it has the characteristics of high speed and long runout distance as well as leading to tremendous damage and economic loss. A large number of field investigations have shown that the runout and area of a flowslide increase with an increase in volume and slope height, but decrease with an increase in slope angle [5-9]. In fact, each flowslide is unique and nonrepeatable, and, as a result, the characteristics and parameters of each are different. Therefore, in field research, it is impossible to separate out the various influencing factors for single factor research. Similarly, data obtained through field investigations cannot accurately reflect the impact of various factors on the characteristics of flowslide movement. To make up for the shortcomings of field investigations, physical model tests were introduced to study the deposit morphology and movement rules of flowslides [10-12]. In the course of these investigations, some rules and interesting characteristics of 
deposits that were in line with reality were reproduced well by model tests. These modeling studies provide a reference for understanding the dynamic characteristics of flowslides. The rationality of experimental method directly determines the accuracy of experimental results $[10,13-15]$. It is prevailing to study the runout distance, influencing factors, stress during movement, and other characteristics of flowslides using model experiments [11]. However, in the research involving the field of flowslides currently, the method is relatively monotonous, and those studies are conducted to the movement and deposit characteristics under the influence of a single factor [4]. In addition, when the order of influencing factors was obtained, a deep excavation on the change laws of deposit morphology and the possible internal mechanical mechanism under the greatest influencing factor has not been performed.

The flowslide flows to the slope break where a change in its flow direction will inevitably cause collision and shearing; the intensity of this effect increases with an increase in slope break angularity and sharpness [13]. The duration of a flowslide increases with angle and volume and decreases with aspect ratio [16]. In the study of the deposit morphology of flowslides, scale effects would affect the overall shape of the deposit including leading edge, highest point, and trailing edge positions, but could be minimized by accurately controlling the test variables [17]. Longitudinal ridges developed on the surface of flowslide deposits caused by radial propagation of the flowslide during movement, as discussed by Dufresne and Davies [18]. The properties of granular materials are also an important factor affecting the characteristics of flowslide deposits, including the granular diameter, the grading index, and the roundness. Different granular materials can lead to different granular effects, which can increase the accumulation area and runout distance $[19,20]$. The apparent friction coefficient is an important parameter used to characterize the movement of a flowslide, which has been widely studied under different variable conditions $[5,7,9,21]$. It is generally believed that the apparent friction coefficient decreases with increasing volume and increases with increasing slope angle, but the related general relationship has not been proposed [3, 22]. Flowslide on alien planets shares the above-mentioned characteristics and rules [23-25] but shows longer runout. At present, research methods used in the study of flowslide are limited, and research schemes are not systematic enough. In addition, better knowledge of the overall rules governing changes in and causes of flowslide deposit morphology is needed.

In this paper, the Taguchi method [15, 26-29] is used to design an experimental scheme and analyze the results of factors affecting the deposit morphology of flowslide. The Taguchi method can be used to quantify test results and to obtain the combination factors that cause the greatest morphological changes in the deposits under test conditions. The specific objectives of this study are to (1) determine the maximum influencing factors of flowslide deposit morphology and the combination of factors that cause the largest change in the morphology of a deposit using the Taguchi method; (2) analyze the changes of the surface and profile morphology of the deposit under the most influential factors and compare them with actual flowslides; (3) explain the rules governing changes in flowslide deposit morphology and carry out the necessary stress analyses for particular morphologies; (4) obtain and confirm the distribution characteristics of the apparent friction coefficient by combining test results with natural flowslides.

\section{Material and Method}

2.1. Sandbox Experiment Setup. A sandbox experiment was conducted to study flowslide deposit morphology. Plexiglass was chosen for the experimental devices, which were composed of four parts: a sand container, an inclined plate, a horizontal plate, and high-speed cameras. The length of both the inclined plate and the horizontal plate is $1.5 \mathrm{~m}$, and the width of each is $1.2 \mathrm{~m}$ (Figure 1(a)). The specification volumes of each sand container with a gate in the bottom are $1.8 \times 10^{-3} \mathrm{~m}^{3}, 3.6 \times 10^{-3} \mathrm{~m}^{3}$, and $5.4 \times 10^{-3} \mathrm{~m}^{3}$. The angle of the inclined plate can be adjusted freely through a rear bracket, and the center gravity height of the sand container can be adjusted through a track on the inclined plate. Highspeed cameras (120 frames/s) were used to record images during the experiment.

During the experiment, medium-fine sand density was controlled to $1.51 \mathrm{~kg} \cdot \mathrm{m}^{-6}$. The material flowed down an inclined plate with no boundary constraints to the horizontal plate when the gate was opened. When the sliding material stopped moving, a millimeter-level three-dimensional scanner was used to collect digital elevation model (DEM) data of the deposit surface (Figure 1(b)) through calibrated and extracted key point coordinates to obtain flowslide deposit morphology data.

2.2. Material. A medium-fine sand (Figure 2) was used as the sliding material in the simulated sandbox experiment because it shows a similar flow characteristic during sliding compared with natural flowslides $[30,31]$; its particle-size distribution curve is shown in Figure 3. The uneven coefficient $C_{u}$ is 2.39 , the curvature coefficient $C_{c}$ is 1.19 , the average diameter is $2 \times 10^{-4} \mathrm{~m}$, and the specific surface area is $0.02 \mathrm{~m}^{2} \cdot \mathrm{kg}^{-4}$. The cumulative percentage of the particle size in the range $0.075-0.5 \mathrm{~mm}$ is $87.71 \%$, the internal friction angle $\varphi$ is $36^{\circ}$, the cohesion $c$ is zero, and the interface friction parameter of plexiglass and sand is 0.538 .

2.3. Method. The experimental scheme was designed using the Taguchi orthogonal method (Table 1) to comprehensively analyze the influence of flowslide volume, slope angle, and slope height on deposit morphology. The following design variables were used to assess influencing factors: volumes $1.8 \times 10^{-3} \mathrm{~m}^{3}, 3.6 \times 10^{-3} \mathrm{~m}^{3}$, and $5.4 \times 10^{-3} \mathrm{~m}^{3}$; slope angles $50^{\circ}, 60^{\circ}$, and $70^{\circ}$; and slope heights $0.7 \mathrm{~m}, 0.9 \mathrm{~m}$, and $1.1 \mathrm{~m}$.

The principle of variable selection was as follows: A K-means clustering of volume and slope height data from 28 flowslides [30] in the Jingyang South platform, Shaanxi province, China, was conducted. Results showed that the 


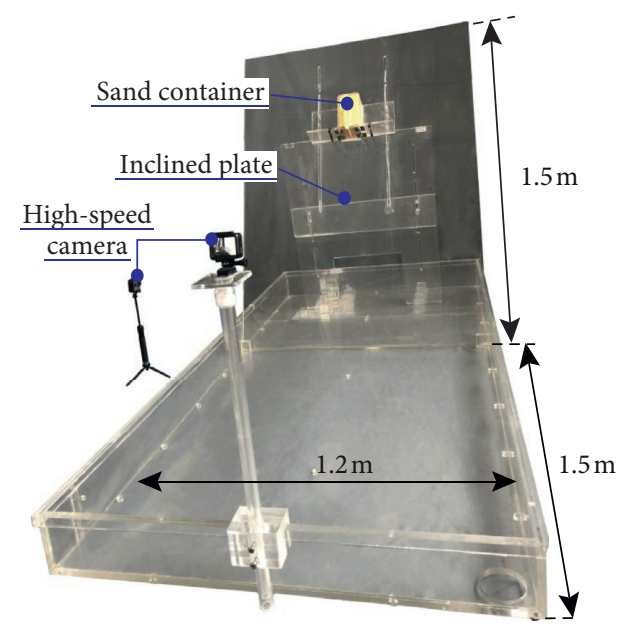

(a)

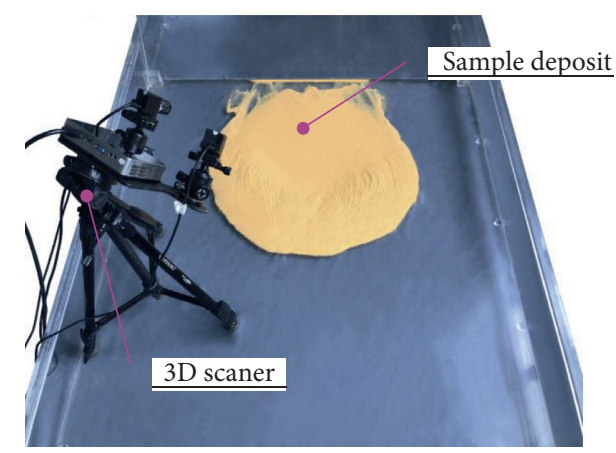

(b)

FIGURE 1: Flowslides experimental research design: (a) structural of the experimental device; (b) 3D scanner for acquisition of deposit data.

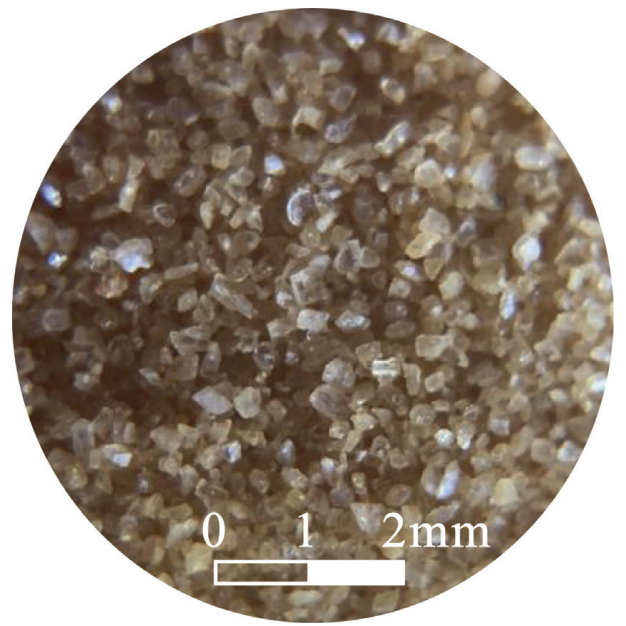

Figure 2: Experimental material.

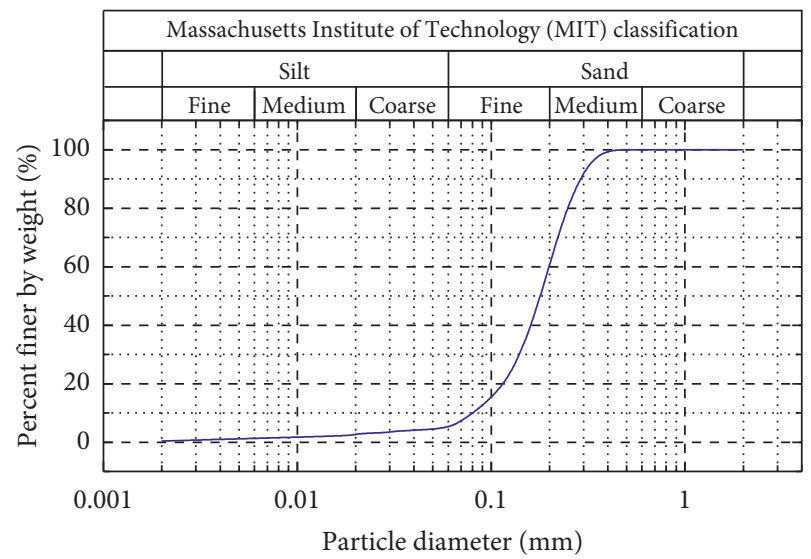

Figure 3: Particle-size distribution curve for the experimental material. deposit volume was divided into three levels of $1317.75 \times 10^{3} \mathrm{~m}^{3}, 545.44 \times 10^{3} \mathrm{~m}^{3}$, and $184.82 \times 10^{3} \mathrm{~m}^{3}$, respectively, so the similarity ratio was approximately 1 : $2 \times 10^{8}$. Slope height was divided into three levels of $113.45 \mathrm{~m}, 84.27 \mathrm{~m}$, and $63.07 \mathrm{~m}$, with a similarity ratio of approximately $1: 100$. The slope angle of the Jingyang South platform was mainly within $40^{\circ}-70^{\circ}$ [31]. There were, in total, nine groups of experiments; two parallel experiments were carried out for each group. If the experimental results were greater than millimeter-level in difference, a third experiment was conducted, eventually taking the average value of two small differences in the results to determine the deposit morphology of the flowslide.

\section{Results}

3.1. Sandbox Experiment Results. The Taguchi method is a test method commonly used in steel casting and other fields within materials science to maximize production and reduce consumables. Its greatest advantage is to determine the order of significance of evaluation indexes using fewer tests and to determine an optimized combination scheme of influencing factors $[15,26,27,29]$. The direct basis for the analysis of the results is the signal-to-noise ratio $(S / N)$, which can be divided into three categories according to three characteristics: larger-the-better, smaller-the-better, and nominal-the-better (washing the test results closest to the target value). The larger the value of $(S / N)$, the greater the signal that the dependent variable responds to the change of factors. Therefore, the larger-the-better characteristic is used in this paper, and the calculation expression is as follows:

$$
\left(\frac{S}{N}\right)_{i}=-10 \lg \left(\frac{1}{n} \sum_{j=1}^{n} Y_{i j}^{2}\right),
$$


TABLE 1: Orthogonal experimental scheme.

\begin{tabular}{lcccc}
\hline Number & Orthogonal combination & Flowslide volume $\left(10^{-3} \mathrm{~m}^{3}\right)$ & Slope angel $\left(^{\circ}\right)$ & Height $(\mathrm{m})$ \\
\hline 1 & $\mathrm{~A}_{1} \mathrm{~B}_{1} \mathrm{C}_{1}$ & 1.8 & 50 & 0.7 \\
2 & $\mathrm{~A}_{1} \mathrm{~B}_{2} \mathrm{C}_{2}$ & 1.8 & 70 & 0.9 \\
3 & $\mathrm{~A}_{1} \mathrm{~B}_{3} \mathrm{C}_{3}$ & 1.8 & 50 & 1.1 \\
4 & $\mathrm{~A}_{2} \mathrm{~B}_{1} \mathrm{C}_{2}$ & 3.6 & 60 & 0.9 \\
5 & $\mathrm{~A}_{2} \mathrm{~B}_{2} \mathrm{C}_{3}$ & 3.6 & 70 & 1.1 \\
6 & $\mathrm{~A}_{2} \mathrm{~B}_{3} \mathrm{C}_{1}$ & 3.6 & 50 & 0.7 \\
7 & $\mathrm{~A}_{3} \mathrm{~B}_{1} \mathrm{C}_{3}$ & 5.4 & 60 & 0.1 \\
8 & $\mathrm{~A}_{3} \mathrm{~B}_{2} \mathrm{C}_{1}$ & 5.4 & 70 & 0.9 \\
9 & $\mathrm{~A}_{3} \mathrm{~B}_{3} \mathrm{C}_{2}$ & 5.4 & 0.9 \\
\hline
\end{tabular}

Note: A, B, and C denote flowslide volume, Slope angle, and height, respectively.

where $(S / N)$ denotes the signal-to-noise ratio; $n$ denotes the repeatable time of each variable combination; $Y_{1 j}$ denotes the observed data of evaluation index; $i$ denotes a different evaluation index, and $j$ is the test number from 1 to $n$.

It is necessary to establish an evaluation index to analyze the influencing factors of flowslide deposit morphology by the Taguchi method, because the deposit morphology of flowslide (Figure 4(a)) can be characterized by five elements, maximum length $\left(L_{d}\right)$, maximum width $\left(W_{d}\right)$, maximum thickness $\left(D_{d}\right)$, area $(A)$, and length-width ratio $\left(L_{d} / W_{d}\right)$ denoted by $Y_{1 j}, Y_{2 j}, Y_{3 j}, Y_{4 j}$, and $Y_{5 j}$, respectively. The five indexes used as evaluation indexes along with statistical results and signal-to-noise ratio calculation results are shown in Tables 2 and 3.

It can be seen from Table 3 that when the volume is $5.4 \times 10^{-3} \mathrm{~m}^{3}$, the slope angle is $70^{\circ}$, the slope height is $0.9 \mathrm{~m}$, and the signal-to-noise ratio values of $L_{d}, W_{d}$, and $A$ are the largest: $40.55,40.49$, and -0.6 , respectively. Therefore, under the influence of this combination, the change responses of $L_{d}, W_{d}$, and $A$ are the largest. It can also be seen that when the volume is $5.4 \times 10^{-3} \mathrm{~m}^{3}$, the slope angle is $50^{\circ}$, the slope height is $1.1 \mathrm{~m}$, and the change response of $D_{d}$ is the largest. When the volume is $1.8 \times 10^{-3} \mathrm{~m}^{3}$, the slope angle is $60^{\circ}$, the slope height is $0.9 \mathrm{~m}$, and the change response of $\left(L_{d} / W_{d}\right)$ is the largest. Based on a comprehensive comparison of a combination of influencing factors $\mathrm{A}_{3} \mathrm{~B}_{3} \mathrm{C}_{2}$-namely, when the volume is $5.4 \times 10^{-3} \mathrm{~m}^{3}$, the slope angle is $70^{\circ}$, and the slope height is $0.9 \mathrm{~m}-$ the change response of the flowslide deposit morphology is the largest.

3.2. Morphology of the Flowslide. The calculation results of the Taguchi method and multivariate analysis of variance both indicate that slope angle has the greatest influence on the deposit morphology of flowslide. To further analyze the morphology of flowslide under the change of slope angle only, an experiment using four sets of sandboxes with a constant volume of $3.6 \times 10^{-3} \mathrm{~m}^{3}$, a constant slope height of $0.9 \mathrm{~m}$, and slope angles of $40^{\circ}, 50^{\circ}, 60^{\circ}$, and $70^{\circ}$ was carried out (Figure 4(b)).

(1) Analysis based on Taguchi method: According to the signal-to-noise ratio values of different combinations determined using equation (1) as listed in Table 3 , the values of the maximum minus minimum (extreme difference) of the signal-to-noise ratio between the three levels under the same factor are obtained (Table 4) and shown in Figure 5. The bigger the extreme difference value of the influencing factors, the greater the influence of this factor on the results $[26,28]$.

The results show that the values of extreme difference of $L_{d}, D_{d}, A$, and $\left(L_{d} / W_{d}\right)$ are $2.77,5.51,4.54$, and 1.7, respectively. The largest value reflects the influence of slope angle as compared with other factors. The next largest value of extreme difference reflects the influence of flowslide volume. The value of extreme difference as influenced by slope height is relatively the smallest. The value of $W_{d}$ is most affected by volume; the corresponding value of extreme difference is 2.78 . In summary, the most significant factor affecting the deposit morphology of flowslide is slope angle, followed by volume and slope height.

(2) Multivariate analysis of variance: To further verify and analyze the impact of flowslide volume, slope angle, and slope height on deposit morphology, a multifactor analysis of variance is conducted on five evaluation indexes influenced by the three factors (Figure 5); the statistical results are shown in Table 5. Partial $\eta^{2}$ (the ratio of the within-group variance to the overall variance of an independent variable) indicates the significance of the effect caused by the influence factor, where the larger the value, the more obvious the effect of the influence factor. The results of multivariate analysis of variance are consistent with the calculation results of the Taguchi method. The values of $L_{d}, D_{d}, A$, and $\left(L_{d} / W_{d}\right)$ corresponding to the biggest partial $\eta^{2}$ are $0.64,0.79,0.56$, and 0.73 , all as a result of the effect of slope angle, while for $W_{d}$, the biggest value is 0.87 , which is the effect of volume of the flowslide. Similarly, the value of partial $\eta^{2}$ under the influence of slope height is relatively the smallest among the five evaluation indexes, which are $0.1,0.24,0.45,0.06$, and 0.05 , respectively. Therefore, slope angle is the factor that has the greatest influence on the deposit morphology of flowslide, followed by volume and slope height. 


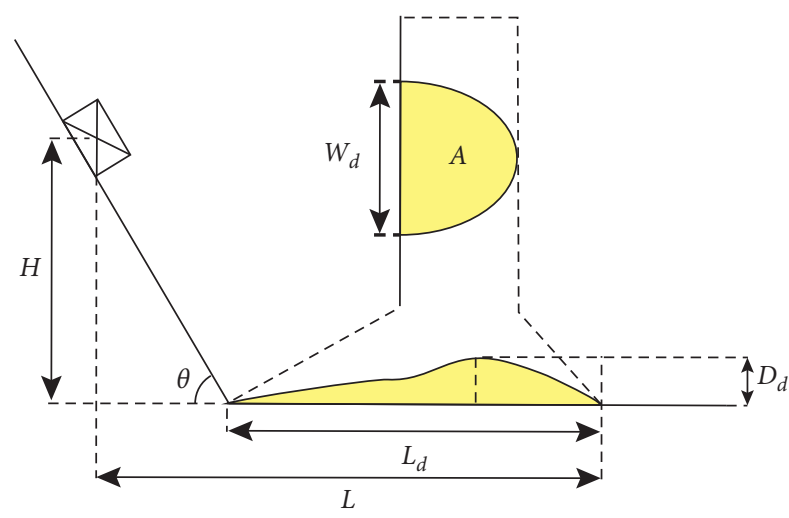

Flowslide deposit

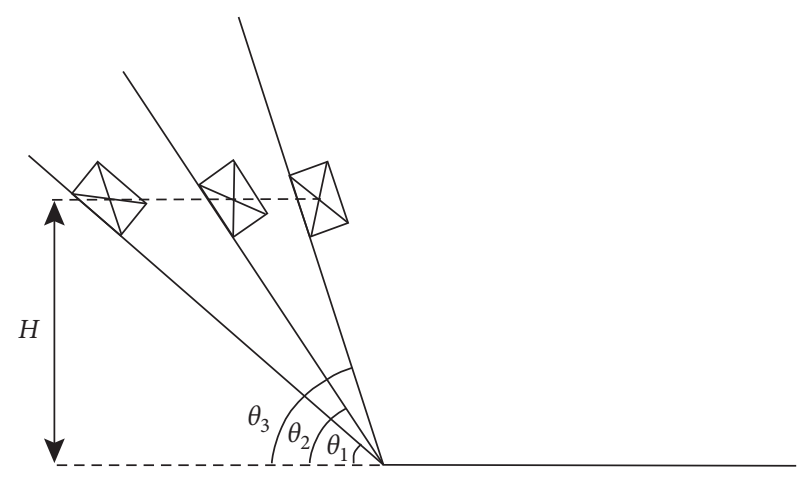

(b)

Figure 4: Schematic illustration of devices: (a) The flowslide deposit characteristics; $L_{d}$ Maximum sliding length of flowslide deposit on the surface; $W_{d}$ Maximum width of flowslide deposit; $D_{d}$ Maximum depth of flowslide deposit; A Area of flowslide deposit projected on horizontal plane; $\theta$ slope angle; $H$ Height of sandbox measuring from center of gravity; $L$ Total sliding distance of flowslide deposit. (b) The process of center gravity constantly.

TABLe 2: Statistics on flowslide deposit morphology.

\begin{tabular}{|c|c|c|c|c|c|}
\hline Orthogonal combination & $Y_{1 j} L_{d}\left(10^{-2} \mathrm{~m}\right)$ & $Y_{2 j} W_{d}\left(10^{-2} \mathrm{~m}\right)$ & $Y_{3 j} D_{d}\left(10^{-2} \mathrm{~m}\right)$ & $Y_{4 j} A\left(\mathrm{~m}^{2}\right)$ & $Y_{5 j}\left(L_{d} / W_{d}\right)(1)$ \\
\hline $\mathrm{A}_{1} \mathrm{~B}_{1} \mathrm{C}_{1}$ & 65.42 & 61.55 & 2.88 & 0.36 & 0.94 \\
\hline $\mathrm{A}_{1} \mathrm{~B}_{2} \mathrm{C}_{2}$ & 68.33 & 70.51 & 1.40 & 0.43 & 1.03 \\
\hline $\mathrm{A}_{1} \mathrm{~B}_{3} \mathrm{C}_{3}$ & 74.63 & 75.01 & 1.32 & 0.47 & 1.01 \\
\hline $\mathrm{A}_{2} \mathrm{~B}_{1} \mathrm{C}_{2}$ & 73.33 & 52.00 & 2.79 & 0.32 & 0.71 \\
\hline $\mathrm{A}_{2} \mathrm{~B}_{2} \mathrm{C}_{3}$ & 94.13 & 90.00 & 1.37 & 0.78 & 0.96 \\
\hline $\mathrm{A}_{2} \mathrm{~B}_{3} \mathrm{C}_{1}$ & 79.27 & 64.51 & 3.23 & 0.44 & 0.81 \\
\hline $\mathrm{A}_{3} \mathrm{~B}_{1} \mathrm{C}_{3}$ & 88.12 & 67.36 & 4.29 & 0.43 & 0.76 \\
\hline $\mathrm{A}_{3} \mathrm{~B}_{2} \mathrm{C}_{1}$ & 95.08 & 88.50 & 2.68 & 0.71 & 0.93 \\
\hline $\mathrm{A}_{3} \mathrm{~B}_{3} \mathrm{C}_{2}$ & 105.76 & 106.50 & 2.78 & 0.93 & 1.01 \\
\hline
\end{tabular}

Note: $L_{d}$, maximum sliding length of flowslide deposit on the surface; $W_{d}$, maximum width of flowslide deposit; $D_{d}$, maximum depth of flowslide deposit; $A$, area of flowslide deposit projected on horizontal plane; $\theta$, slope angle; $\left(L_{d} / W_{d}\right)$, length-width ratio.

TABLE 3: The signal-to-noise ratio of elements of deposits morphology.

\begin{tabular}{|c|c|c|c|c|c|}
\hline \multirow{2}{*}{ Orthogonal combination } & \multicolumn{5}{|c|}{ Signal-to-noise ratio $(\mathrm{dB})$} \\
\hline & $L_{d}\left(10^{-2} \mathrm{~m}\right)$ & $W_{d}\left(10^{-2} \mathrm{~m}\right)$ & $D_{d}\left(10^{-2} \mathrm{~m}\right)$ & $A\left(\mathrm{~m}^{2}\right)$ & $\left(L_{d} / W_{d}\right)(1)$ \\
\hline $\mathrm{A}_{1} \mathrm{~B}_{1} \mathrm{C}_{1}$ & 35.79 & 36.31 & 9.19 & -8.76 & -0.53 \\
\hline $\mathrm{A}_{1} \mathrm{~B}_{2} \mathrm{C}_{2}$ & 36.97 & 36.69 & 2.92 & -7.29 & 0.27 \\
\hline $\mathrm{A}_{1} \mathrm{~B}_{3} \mathrm{C}_{3}$ & 37.5 & 37.46 & 2.41 & -6.51 & 0.04 \\
\hline $\mathrm{A}_{2} \mathrm{~B}_{1} \mathrm{C}_{2}$ & 34.32 & 37.31 & 8.91 & -9.91 & -2.99 \\
\hline $\mathrm{A}_{2} \mathrm{~B}_{2} \mathrm{C}_{3}$ & 39.09 & 39.48 & 2.73 & -2.1 & -0.39 \\
\hline $\mathrm{A}_{2} \mathrm{~B}_{3} \mathrm{C}_{1}$ & 36.19 & 37.98 & 10.18 & -7.08 & -1.79 \\
\hline $\mathrm{A}_{3} \mathrm{~B}_{1} \mathrm{C}_{3}$ & 36.57 & 38.9 & 12.65 & -7.3 & -2.33 \\
\hline $\mathrm{A}_{3} \mathrm{~B}_{2} \mathrm{C}_{1}$ & 38.94 & 39.56 & 8.56 & -2.95 & -0.62 \\
\hline $\mathrm{A}_{3} \mathrm{~B}_{3} \mathrm{C}_{2}$ & 40.55 & 40.49 & 8.88 & -0.6 & 0.06 \\
\hline
\end{tabular}

Note: $L_{d}$, maximum sliding length of flowslide deposit on the surface; $W_{d}$, maximum width of flowslide deposit; $D_{d}$, maximum depth of flowslide deposit; $A$, area of flowslide deposit projected on horizontal plane; $\theta$, slope angle; $\left(L_{d} / W_{d}\right)$, length-width ratio.

3.3. Planar Morphology at Different Angles. After correcting the digital elevation model (DEM) data obtained by the scanner, the three-dimensional coordinates of the flowslide deposit are extracted and the contour maps of the surface morphology are drawn (Figure 6). At smaller slope angles of $40^{\circ}$ and $50^{\circ}$, the deposit surface is relatively flat, its long axis lies along the width of the flowslide, and it is generally tongue-shaped. At $40^{\circ}$, the length, width, length-width ratio, and area are $0.53 \mathrm{~m}, 0.70 \mathrm{~m}, 0.76$, and $0.29 \mathrm{~m}^{2}$, respectively. At $50^{\circ}$, the length, width, length-width ratio, and area are $0.89 \mathrm{~m}, 0.80 \mathrm{~m}, 1.11$, and $0.44 \mathrm{~m}^{2}$, respectively, while at larger slope angles of $60^{\circ}$ and $70^{\circ}$, the deposits tend to be thickest at 
TABLE 4: The main factors of influence.

\begin{tabular}{|c|c|c|c|c|c|c|}
\hline Morphological elements of deposit & Influencing factors & Level1 $(\mathrm{dB})$ & Level2 $(\mathrm{dB})$ & Level3 (dB) & Extreme difference $(\mathrm{dB})$ & Influence order \\
\hline \multirow{3}{*}{$L_{d}(\mathrm{~m})$} & $\mathrm{A}$ & 36.75 & 36.52 & 38.69 & 2.16 & 2 \\
\hline & $\mathrm{B}$ & 35.56 & 38.33 & 38.08 & 2.78 & 1 \\
\hline & $\mathrm{C}$ & 36.97 & 37.28 & 37.72 & 0.75 & 3 \\
\hline \multirow{3}{*}{$W_{d}(\mathrm{~m})$} & $\mathrm{A}$ & 36.82 & 38.25 & 39.65 & 2.78 & 1 \\
\hline & $\mathrm{B}$ & 37.51 & 38.58 & 38.64 & 1.08 & 2 \\
\hline & $\mathrm{C}$ & 37.95 & 38.16 & 38.66 & 0.71 & 3 \\
\hline \multirow{3}{*}{$D_{d}(\mathrm{~m})$} & $\mathrm{A}$ & 4.82 & 7.28 & 10.03 & 5.21 & 2 \\
\hline & $\mathrm{B}$ & 10.25 & 4.74 & 7.16 & 5.51 & 1 \\
\hline & $\mathrm{C}$ & 9.31 & 6.91 & 5.93 & 3.38 & 3 \\
\hline \multirow{3}{*}{$A\left(\mathrm{~m}^{2}\right)$} & $\mathrm{A}$ & -7.52 & -6.37 & -3.62 & 3.90 & 2 \\
\hline & B & -8.66 & -4.11 & -4.73 & 4.54 & 1 \\
\hline & $\mathrm{C}$ & -6.27 & -5.93 & -5.31 & 0.96 & 3 \\
\hline \multirow{3}{*}{$\left(L_{d} / W_{d}\right)$} & $\mathrm{A}$ & -0.07 & -1.72 & -0.97 & 1.65 & 2 \\
\hline & B & -1.95 & -0.25 & -5.61 & 1.70 & 1 \\
\hline & C & -0.98 & -0.90 & -0.89 & 0.09 & 3 \\
\hline
\end{tabular}

Note: A, B, and C denote flowslide volume, slope angle, and height, respectively. $L_{d}$, maximum sliding length of flowslide deposit on the surface; $W_{d}$, maximum width of flowslide deposit; $D_{d}$, maximum depth of flowslide deposit; $A$, area of flowslide deposit projected on horizontal plane; $\theta$, slope angle; $\left(L_{d} / W_{d}\right)$, length-width ratio.

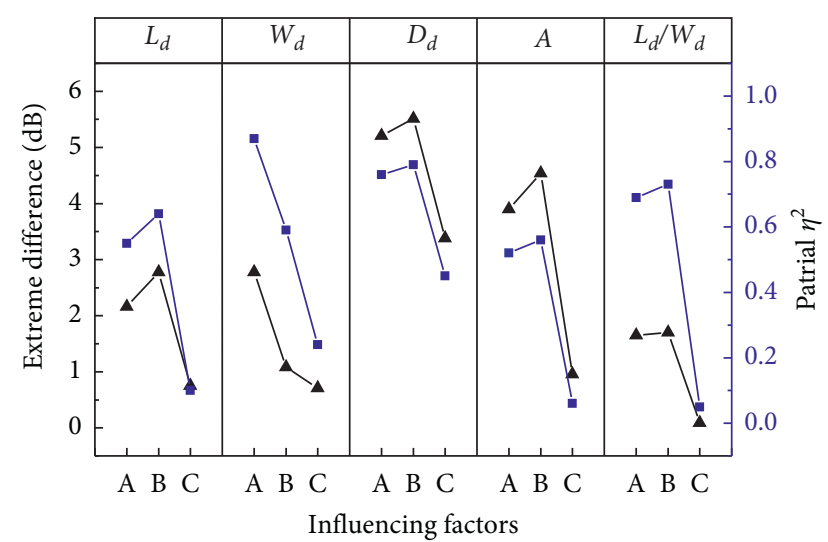

FIgURE 5: Statistical results using Taguchi method and multivariate analysis of variance.

the front and back and are nearly round; upheaval and wash are arranged alternately on the surface. At $60^{\circ}$, the length, width, length-width ratio, and area are $0.90 \mathrm{~m}, 0.90 \mathrm{~m}, 1.0$, and $0.57 \mathrm{~m}^{2}$, respectively. At $70^{\circ}$, the length, width, lengthwidth ratio, and area are $0.74 \mathrm{~m}, 0.75 \mathrm{~m}, 0.99$, and $0.42 \mathrm{~m}^{2}$, respectively. The morphologies of the flowslides formed at each of the four angles are symmetrically distributed about the sliding central axis.

Comparing the shape of the deposits formed at each of the four angles, we can see that, with an increase in slope angle, the values of $L_{d}, W_{d}, A$, and $\left(L_{d} / W_{d}\right)$ for the flowslide deposit first increase and then decrease. The main reason is that, by increasing slope angle from $40^{\circ}$ to $60^{\circ}$, the sum of kinetic energy loss by the sliding body due to friction and collisional energy loss on the slope break is reduced. However, in increasing the slope angle from $60^{\circ}$ to $70^{\circ}$, the sum of the kinetic energy loss and the collisional energy loss increases. In the experiment, the slope height was kept at a constant value of $0.90 \mathrm{~m}$ to each of the four angles, so the initial potential energy was the same for each (Figure 4(b)).
The smaller the slope angle, the greater the moving displacement of the sliding body on the inclined plate, resulting in greater kinetic energy loss caused by friction. When the flowslide flows to a slope break where there is a change in the direction of motion to a horizontal direction, and kinetic energy loss will inevitably occur; kinetic energy loss is positively related to the slope angle [32]. Under the condition of changing angles, the increase in the length of the flowslide deposit is significantly higher than the width. This is explained by the feature of straightness [33], which the flowslide has during high-speed movement.

These laboratory findings can be examined in the context of flowslides that occurred naturally. In Xihetan, Shaanxi province, China, a low-angle flowslide deposit formed at a $45^{\circ}$ slope angle and had a length of $289 \mathrm{~m}$, a width of $329 \mathrm{~m}$, and a length-width ratio of 0.88 (Figure 7). Another lowangle deposit formed in Shenzhen, China [34, 35], on a slope angle of $24^{\circ}$ with a length of $700 \mathrm{~m}$, a width of about $550 \mathrm{~m}$, and a length-width ratio of about 1.27 (Figure 8). A large slope angle (more than $60^{\circ}$ ) slide on the steep cliffs along the coast of Northern Europe is shown in Figure 9. The following are shown: in Figure 9(a), the deposit with a length $330 \mathrm{~m}$, in Figure 9(b), the deposit with a length $150 \mathrm{~m}$, in Figure 9(c), the deposit with a length $150 \mathrm{~m}$ and width $120 \mathrm{~m}$, in Figure $9(\mathrm{~d})$, the deposit with a length $270 \mathrm{~m}$ and width $300 \mathrm{~m}$, all of these deposits with a length-width ratio close to 1 , alternating upheaval and wash on the surface of the deposit, and an overall circular shape (Figure 9) $[36,37]$. The actual flowslides at small angles and large angles are similar to the deposit morphology and state of motion formed during the current experiment. However, due to the difference in topography and the scale of the actual flowslides, it is difficult to compare in terms of dimensional parameters, such as the length and width of the deposit, leaving the dimensionless length-width ratio, surface morphology, and overall shape for comparison. In both the natural and the modeled deposit morphology, a flat surface and a generally 
TABLE 5: Variance analysis statistics.

\begin{tabular}{|c|c|c|c|c|c|}
\hline Morphological elements of deposit & Factors & Quadratic sum & DOF & Mean square error & Partial $\eta^{2}$ \\
\hline \multirow{5}{*}{$L_{d}(\mathrm{~m})$} & $\mathrm{A}$ & 686.28 & 2 & 343.14 & 0.55 \\
\hline & $\mathrm{B}$ & 987.32 & 2 & 493.66 & 0.64 \\
\hline & $\mathrm{C}$ & 59.7 & 2 & 29.85 & 0.1 \\
\hline & Error & 564.58 & 2 & 282.29 & \\
\hline & Total & 2297.87 & 8 & & \\
\hline \multirow{5}{*}{$W_{d}(\mathrm{~m})$} & A & 1083.03 & 2 & 541.51 & 0.87 \\
\hline & $\mathrm{B}$ & 224.48 & 2 & 112.24 & 0.59 \\
\hline & C & 48.97 & 2 & 24.49 & 0.24 \\
\hline & Error & 158.35 & 2 & 79.17 & \\
\hline & Total & 1514.83 & 8 & & \\
\hline \multirow{5}{*}{$D_{d}(\mathrm{~m})$} & $\mathrm{A}$ & 2.89 & 2 & 1.44 & 0.76 \\
\hline & $\mathrm{B}$ & 3.42 & 2 & 1.71 & 0.79 \\
\hline & $\mathrm{C}$ & 0.73 & 2 & 0.37 & 0.45 \\
\hline & Error & 0.91 & 2 & 0.45 & \\
\hline & Total & 7.95 & 8 & & \\
\hline \multirow{5}{*}{$A\left(\mathrm{~m}^{2}\right)$} & $\mathrm{A}$ & 0.11 & 2 & 0.06 & 0.52 \\
\hline & $\mathrm{B}$ & 0.13 & 2 & 0.07 & 0.56 \\
\hline & C & 0.01 & 2 & 0 & 0.06 \\
\hline & Error & 0.11 & 2 & 0.05 & \\
\hline & Total & 0.36 & 8 & & \\
\hline \multirow{5}{*}{$\left(L_{d} / W_{d}\right)$} & $\mathrm{A}$ & 0.04 & 2 & 0.02 & 0.69 \\
\hline & $\mathrm{B}$ & 0.05 & 2 & 0.03 & 0.73 \\
\hline & C & 0 & 2 & 0 & 0.05 \\
\hline & Error & 0.02 & 2 & 0.01 & \\
\hline & Total & 0.11 & 8 & & \\
\hline
\end{tabular}

Note: $L_{d}$, maximum sliding length of flowslide deposit on the surface; $W_{d}$, maximum width of flowslide deposit; $D_{d}$, maximum depth of flowslide deposit; $A$, area of flowslide deposit projected on horizontal plane; $\theta$, slope angle; $\left(L_{d} / W_{d}\right)$, length-width ratio.

tongue-shaped deposit form at low angles, while alternating upheaval and wash on the deposit surface and a generally circle-shaped deposit form at large angles.

3.4. Profile Morphology at Different Angles. Multidimensional analysis of the morphology of flowslide deposit can help researchers gain a deeper understanding of morphology characteristics. Figure 10 shows the profiles of the four flowslides depicted in Figure 6. Combining the profile (Figure 10) with planar morphology (Figure 6), it can be seen that, at smaller slope angles of $40^{\circ}$ and $50^{\circ}$, a generally single upheaval with heights of $0.027 \mathrm{~m}$ and $0.018 \mathrm{~m}$ can be recognized with corresponding peak positions of $0.28 \mathrm{~m}$ and $0.50 \mathrm{~m}$, respectively, although the surface of each deposit is slightly undulated. The position of the center of gravity is consistent with the peak position of the upheaval. At larger slope angles of $60^{\circ}$ and $70^{\circ}$, the surfaces of the deposits are undulated and there is double upheaval. The maximum height differences between adjacent upheaval and wash are $0.005 \mathrm{~m}$ and $0.023 \mathrm{~m}$, respectively. The heights of the front upheaval are $0.009 \mathrm{~m}$ and $0.026 \mathrm{~m}$ with corresponding peak positions of $0.67 \mathrm{~m}$ and $0.40 \mathrm{~m}$, respectively. The heights of the back upheaval are $0.012 \mathrm{~m}$ and $0.035 \mathrm{~m}$ with corresponding peak positions of $0.10 \mathrm{~m}$ and $0.06 \mathrm{~m}$, respectively. The heights of the middle wash are $0.006 \mathrm{~m}$ and $0.011 \mathrm{~m}$ with corresponding positions of $0.41 \mathrm{~m}$ and $0.22 \mathrm{~m}$, respectively. The positions of the center of gravity are relatively consistent with the position of the middle wash.
Comparing the four profiles shows a single upheaval shape at smaller angles of $40^{\circ}$ and $50^{\circ}$ and a double upheaval shape at larger angles of $60^{\circ}$ and $70^{\circ}$. In the flowslides with double upheaval, the height of the front upheaval is smaller than that of the back upheaval. As the slope angle increases, the average thickness of the deposit first decreases and then increases, and the position of the center of gravity first advances and then retreats. Based on the above comparison, it can be considered that there should be a key angle in the change laws of flowslide deposit morphology. If the slope angle is less than or larger than the key angle under the same conditions, the length and width of the deposit will decrease. The key angle is between $60^{\circ}$ and $70^{\circ}$ under the experimental conditions in the paper. However, actually, the key angle of flowslides should be different values depending on the material of the sliding body and the terrain conditions.

The profile figures of chalk flows [36] on the steep cliffs of the European coast show similarities with the profile morphology of the sandbox experiment for the larger angles, especially the feature of double upheaval (Figures 11 and 12). These two deposits shown in Figures 11 and 12 are $320 \mathrm{~m}$ and $200 \mathrm{~m}$ in length, respectively. It can be seen from the picture that the leading edge of the flowslide deposit is flat and the surface shows double upheaval. The front upheaval is lower than the back upheaval. The height difference between the middle wash and the back upheaval is greater than that of the front upheaval. The center of gravity is located slightly in front of the middle wash. It is noticed that there is a difference although the morphology of the double 


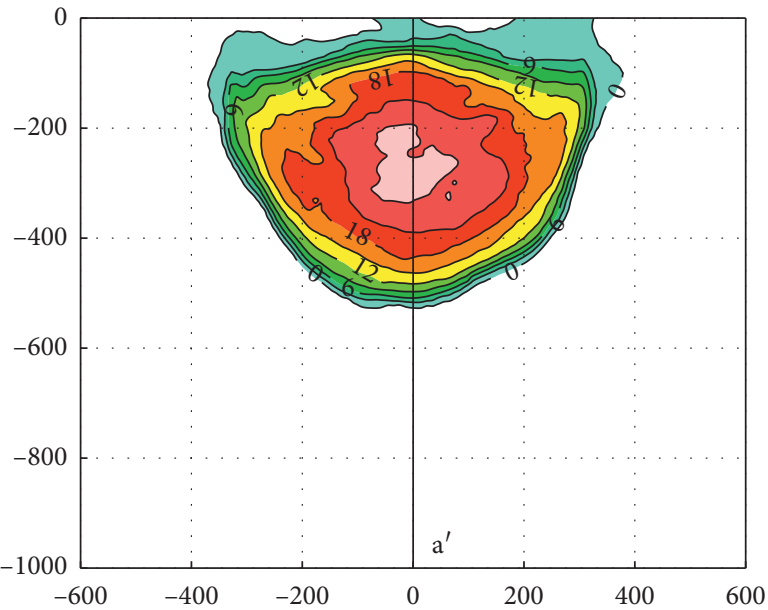

(a)

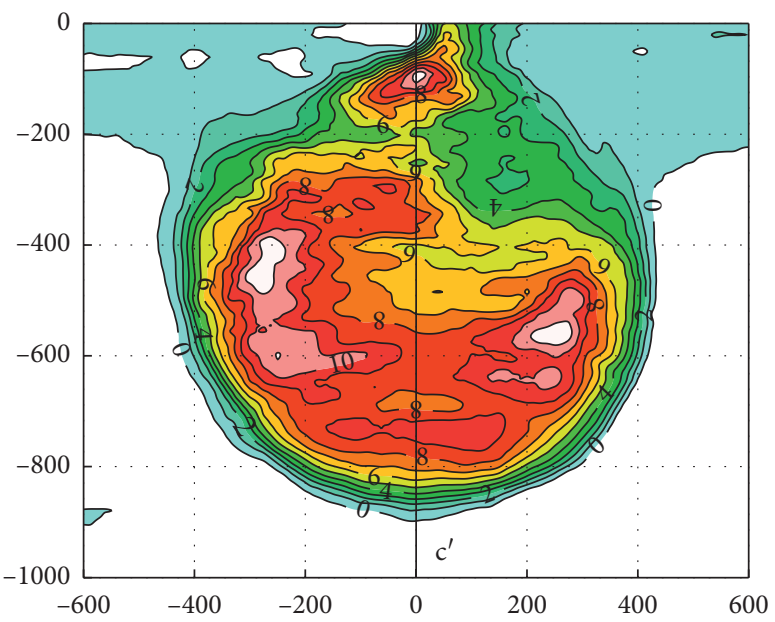

(c)

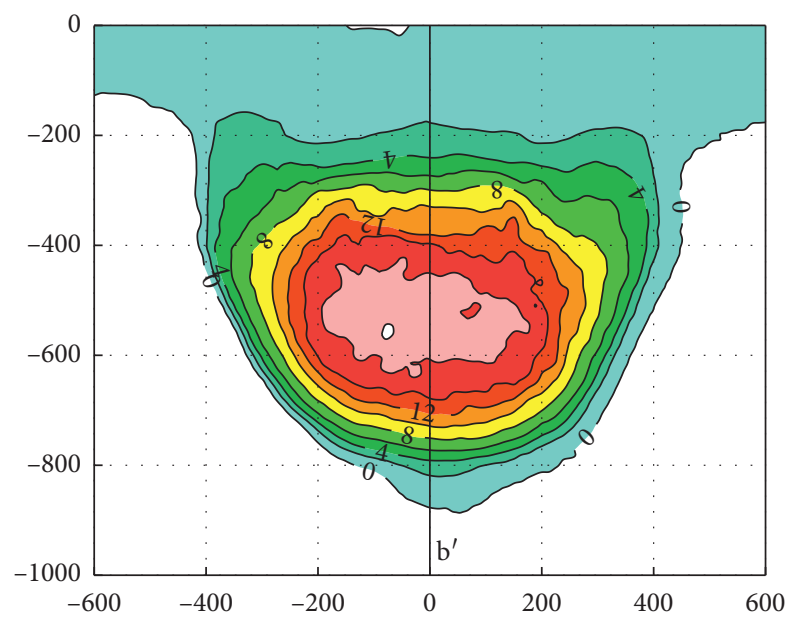

(b)

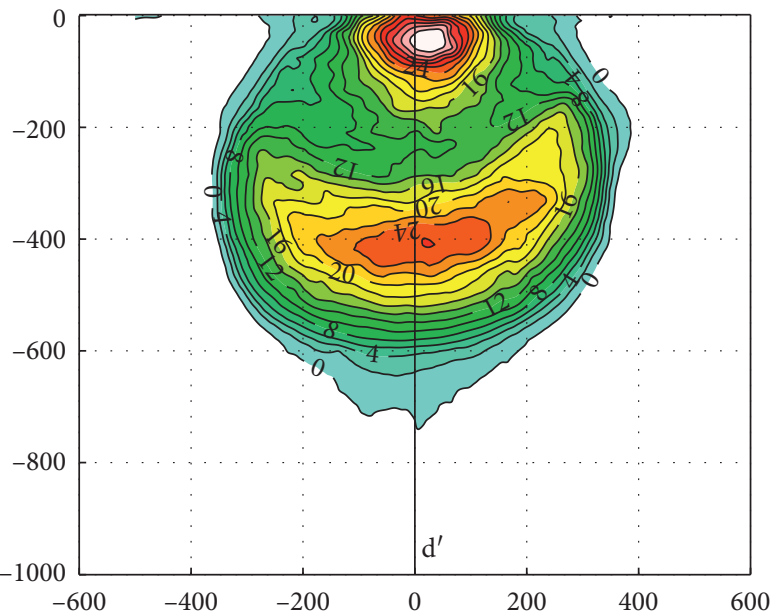

(d)

Figure 6: Contour map of flowslides topography at different slope angles: (a), (b), (c) and (d) corresponding to $40^{\circ}, 50^{\circ} 60^{\circ}$ and $70^{\circ}$, respectively.

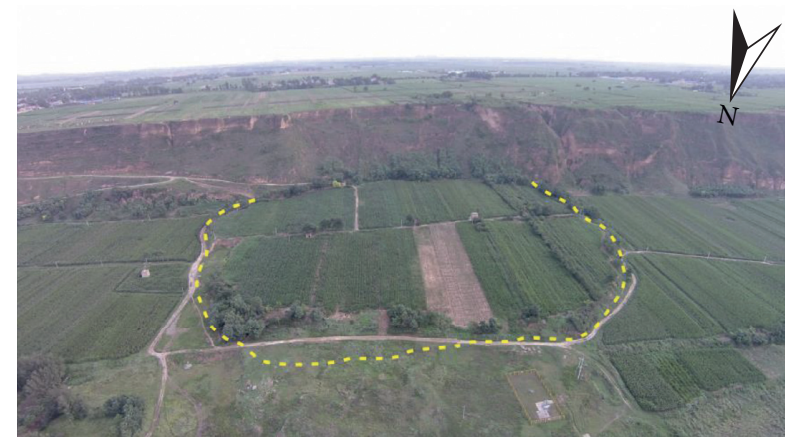

Figure 7: Xi Hetan flowslide, in China $\left(34^{\circ} 29^{\prime} 32^{\prime \prime} \mathrm{N} 108^{\circ} 50^{\prime} 13^{\prime \prime} \mathrm{E}\right)$.

upheaval is the same. The center of gravity of flowslide deposit is located in the middle wash in experimental conditions. However, the center of gravity is located in front of the middle wash in actual flowslides. The possible reason mainly is the difference of properties of granular materials, because the movement and accumulation process of flowslides are also affected by internal factors such as the particle size and roundness of sliding body materials [14].

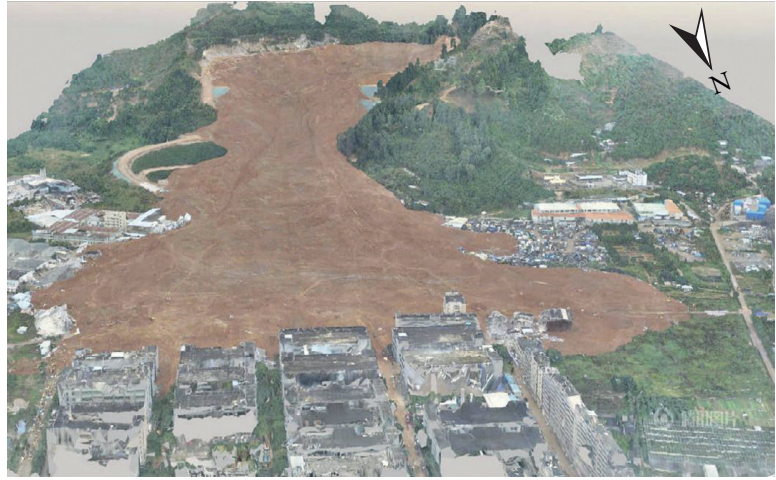

Figure 8: Shenzhen flowslide. Source: Aerial image form Souhu.com, in China $\left(22^{\circ} 43^{\prime} 04^{\prime \prime} \mathrm{N} 113^{\circ} 56^{\prime} 31^{\prime \prime} \mathrm{E}\right)$.

3.5. Mechanical Analysis of the Deposit Morphology. Before the mechanical analysis, the properties of the medium-fine sand and plexiglass should be noticed as a basis for this analysis. The friction coefficient 0.727 of the medium-fine sand is larger than 0.538 of the interface of 


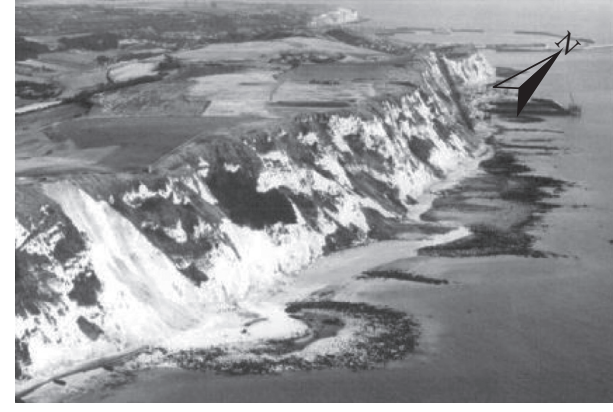

(a)

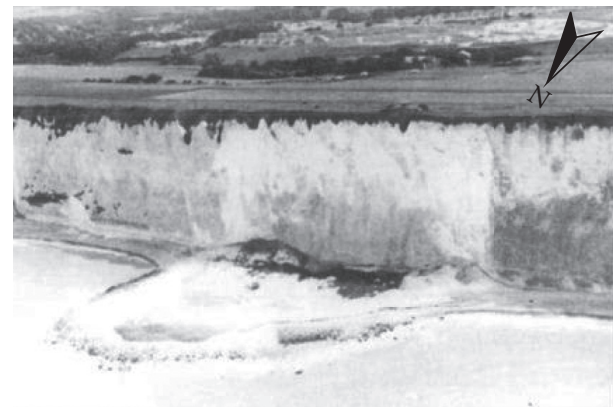

(c)

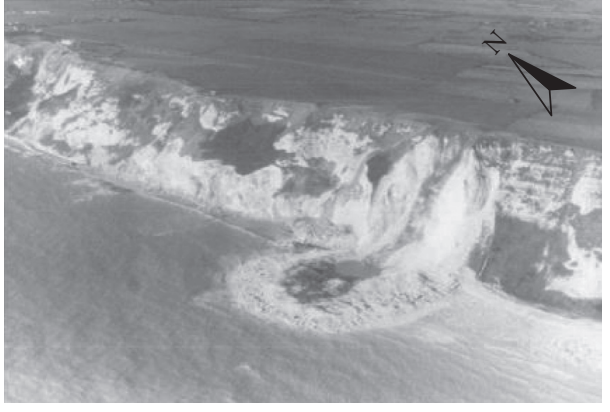

(b)

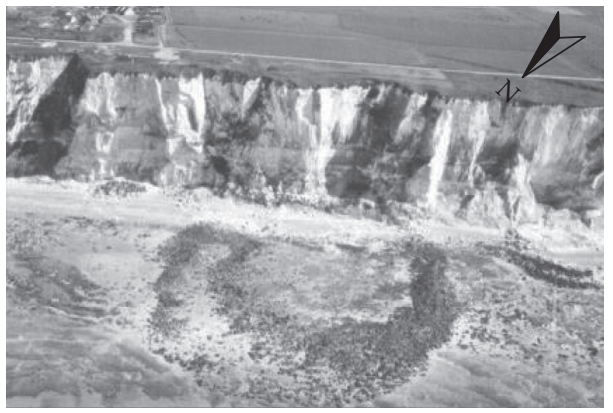

(d)

Figure 9: Topography of typical flowslides. (a) and (b) located in Folkestone Warren $\left(51^{\circ} 05^{\prime} 03^{\prime \prime} \mathrm{N} 1^{\circ} 20^{\prime} 36^{\prime \prime}\right.$ E), (c) and (d) located Dover, Kent $\left(51^{\circ} 07^{\prime} 53^{\prime \prime} \mathrm{N} 1^{\circ} 20^{\prime} 36^{\prime \prime}\right.$ E). Source from Hutchinson [36].

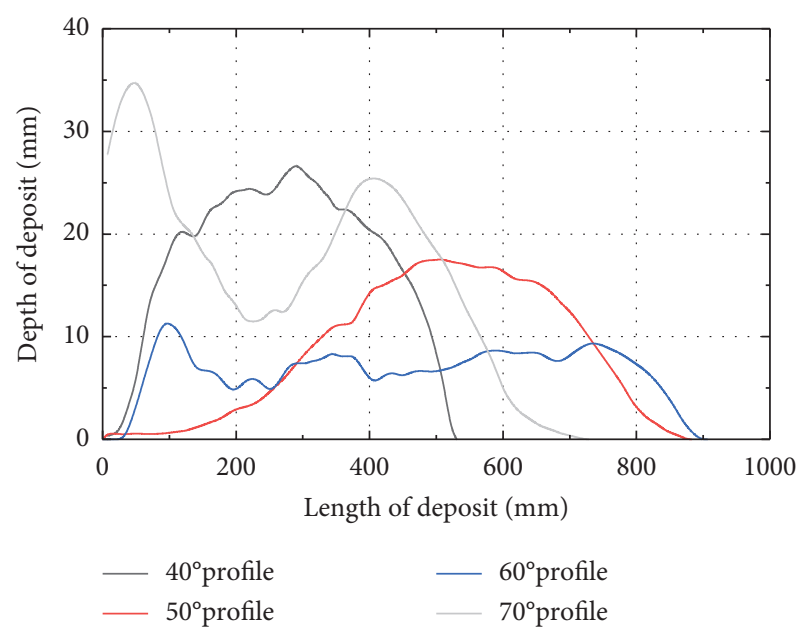

Figure 10: The deposit profiles of flowslides at different angles.

the plexiglass with the medium-fine sand. The difference of the friction coefficient between the interface and the sliding body itself also existed in actual flowslides because the interface will be lubricated by water or the liquefaction effect $[30,38]$. Therefore, the sliding body tends to flow along the interface of the plexiglass, and the sand forms a thin sand layer like an erodible bed before the main sliding body arrived on both inclined and horizontal plates $[39,40]$. It provides an essential condition of the shear action. Figure 13 shows the cross-sectional state of the sliding body at three phases, in which phase 3 , indicated by a solid line, represents the final deposit state of the

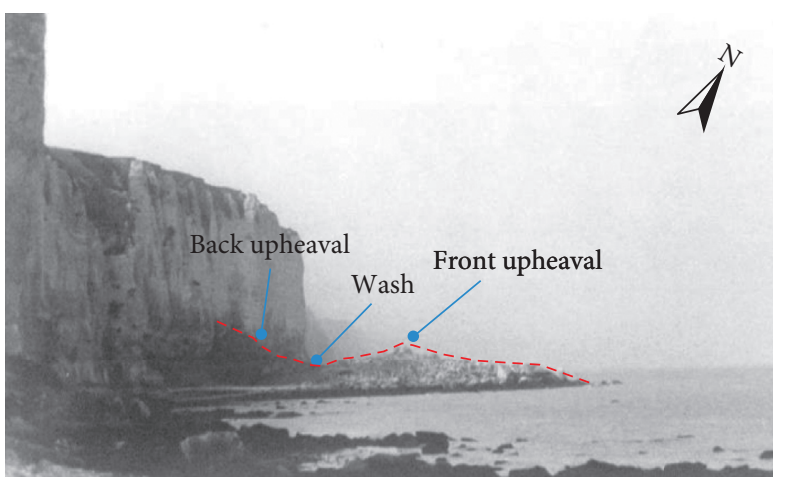

Figure 11: Flowslide occurred in May 1981 at Le Chien Neuf $\left(49^{\circ} 46^{\prime} 59^{\prime \prime} \mathrm{N} 0^{\circ} 25^{\prime} 19^{\prime \prime}\right.$ E). Source from Hutchinson [36].

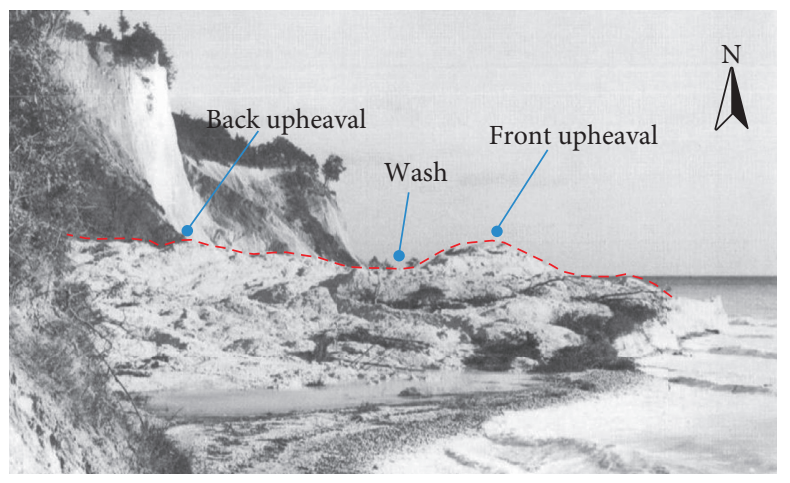

FIgURE 12: Flowslide occurred in May 1958 at Wissower Klinken, Rügen, Germany $\left(54^{\circ} 32^{\prime} 09^{\prime \prime} \mathrm{N} 13^{\circ} 40^{\prime} 42^{\prime \prime} \mathrm{E}\right)$. Source from Hutchinson [36]. 


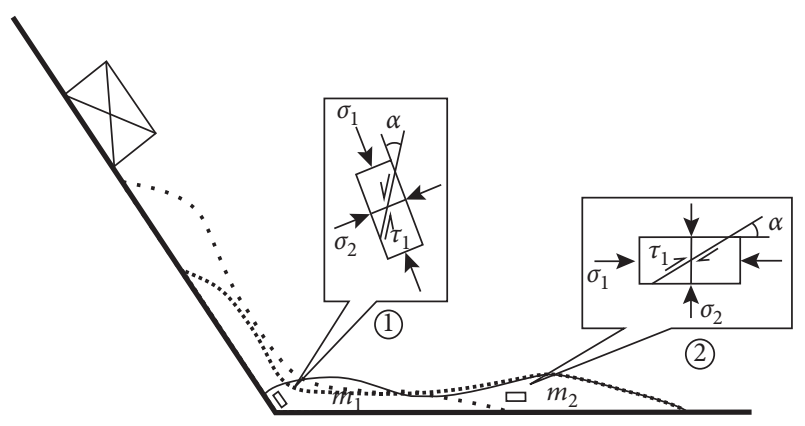

...... Phase 1

..... Phase 2

- Phase 3

Figure 13: Schematic illustration of shear force of flowslide.

sliding body. In this paper, the Mohr-Coulomb criterion is used in the analysis of the formation of single and double upheaval as follows:

$$
\tau=c+\sigma \tan \varphi .
$$

Taking the numbers (1) and (2) as two microelements in the sliding body, under a stress condition whereby the maximum principal stress $\sigma_{1}$ of the microelement at the slope break is parallel to the direction of the inclined plate and the confining pressure $\sigma_{2}=\sigma_{3}$ is perpendicular to the direction of the inclined plate (the microelements are small enough, so it is considered that $\sigma_{2}=\sigma_{3}$ ), shear behavior occurs $[22,30,31]$.

The angle between the shear plane and the maximum principal stress is defined as $45^{\circ}-(\varphi / 2)$, and the friction angle $\varphi$ in the sand material is $36^{\circ}$. For a microelement (1) at smaller slope angles of $40^{\circ}$ and $50^{\circ}$, the counterclockwise angles between the shear action direction and the overall movement direction of the flowslide are $167^{\circ}$ and $157^{\circ}$, respectively, tending to horizontal, which is approximately the same as the direction of the maximum principal stress in the state of the microelement (2), which will be a source of power for the morphology of single upheaval. Afterwards, the microelements located on the horizontal plate move along the shear plane at an angle of $27^{\circ}$ counterclockwise with the movement direction of the sliding body on the horizontal plate under the obstruction of the other particles in the front and the push of rear particles, similar to a thrust nappe in macroscopic performance, resulting in deposit morphology as a single upheaval.

The formation of double upheaval is more complicated. Here, it will be described according to the order of the front upheaval, the wash, and the back upheaval. First, based on the same calculation method as for the smaller angles, the counterclockwise angles between the shear-action direction of the microelement (1) and the movement direction of the sliding body on the horizontal plate are $93^{\circ}$ and $83^{\circ}$ at the larger slope angles of $60^{\circ}$ and $70^{\circ}$, respectively. At this point, the sliding body deposits part of its load under the actions of shear force and thrust force to form a rudiment of the front upheaval, while the part of the sliding body on the horizontal plate keeps moving under the inertial force and the thrust force of the back part sliding body (the force state is similar to the microelement (2) and continues development of the front upheaval gradually. Next, the microelements at the back of the front upheaval stop their shearing motion when the equilibrium condition of equation (3) is satisfied; climbing is stopped, and the wash is formed. However, mechanical conditions still allow the microelements to move horizontally. When the equilibrium condition of equation (4) is satisfied, the horizontal movement stops. Assuming that the microelements are small enough, the equilibrium condition can be listed as follows:

$$
\begin{aligned}
& m \cdot g=\tau \cdot \sin \left(45^{\circ}-\frac{\varphi}{2}\right), \\
& m \cdot a=\tau \cdot \cos \left(45^{\circ}-\frac{\varphi}{2}\right),
\end{aligned}
$$

where $m$ is the mass of the microelement, $g$ is the acceleration of gravity, $\tau$ is shear stress, a is the horizontal acceleration of the microelement, and $\varphi$ is the friction angle of sand material.

Eventually, under the balance of equations (3) and (4), the sliding body that is still moving at the trailing edge is very small, as the speed, so the shear force provided can be reduced accordingly. At this time, if the internal shearing force of the sliding body at the trailing edge is greater than the shearing strength of the sliding body, the subsequent sliding body is deposited at the foot of the slope to form the back upheaval and conducts a localized shear motion based on the shear force similar to the microelement (1); however, if the shear force is less than the shear strength of the sliding body, then the sliding body deposits at the slope break to form the back upheaval. In general, the order of the formation process of the double upheaval is front upheaval, wash, and back upheaval.

The formation of double upheaval morphology is also owing to properties of the granular material. In this study, there is a double upheaval morphology; nevertheless, this is not in the study by $\mathrm{Hu}$ [14]. The range of the granular particle from $5 \times 10^{-6} \mathrm{~m}$ to $4 \times 10^{-4} \mathrm{~m}$ in this article is obviously less than the range of the granular particle from $10^{-3} \mathrm{~m}$ to $1.6 \times 10^{-2} \mathrm{~m}$ in the research by $\mathrm{Hu}$ [14]. Therefore, the internal friction angle and cohesion of the experimental material in this study are larger than those in the research by $\mathrm{Hu}$ [14]. The more the internal friction angle and cohesion of granular materials are, the more the difficult to disturb the state of the deposit morphology [19] is. When the front upheaval is formed, the granular material with a particle size of $5 \times 10^{-6} \mathrm{~m}$ to $4 \times 10^{-4} \mathrm{~m}$ is more likely to keep its morphology of the front upheaval in the disturbance of the back sliding body compared with a particle size of $10^{-3} \mathrm{~m}$ to $1.6 \times 10^{-2} \mathrm{~m}$. If the backsliding body can not disturb the formed front upheaval, it will accumulate in the slope break forming the back upheaval meanwhile, whereupon the double upheaval is formed.

For these change laws, as the slope angle increases, the maximum width, maximum length, and area of the deposit first increase and then decrease, similar to the results by $\mathrm{Hu}$ [14] at the condition of the mass of fine particles changes. 
Based on those results, a conclusion was proposed that there is an optimum proportion of fine and coarse particles in the granular materials, because the shear strength and friction coefficient are increasing with the mass of fine particles increases [41, 42]. In the condition that the internal friction angle and cohesion are the smallest, the maximum width, maximum length, and area are maximum. Hence, the deduction mentioned before is reasonable that there should be a critical slope angle in the changes of the deposit morphology.

3.6. Apparent Friction Coefficient. To further understand the rules that govern changes in the apparent friction coefficient with slope angle and the distribution characteristics of the apparent friction coefficient in different lithologies and different regions, the apparent friction coefficients and corresponding slope angle data were collected for research from three places. There are 28 soil flowslides in the Jingyang South platform $\left(34^{\circ} 29^{\prime} 32^{\prime \prime} \mathrm{N}, 108^{\circ} 50^{\prime} 13^{\prime \prime} \mathrm{E}\right)$, Shaanxi province, China [30], consisting of loess. The accumulation area is the even river terrace, comprised of the loess deposit, underlain by the silty clay deposit with interbedded sand layers occasionally. Along the coast of northern Europe $\left(51^{\circ} 05^{\prime} 03^{\prime \prime} \mathrm{N}, 1^{\circ} 20^{\prime} 36^{\prime \prime} \mathrm{E}\right)$, there are 27 chalk flows [22] with a porosity ranging from $9 \%$ to $52 \%$ and dry density ranging from 24.13 to $12.65 \mathrm{kN} / \mathrm{m}^{3}$. In Wenchuan $\left(31^{\circ} 00^{\prime} 00^{\prime \prime} \mathrm{N}, 103^{\circ} 40^{\prime} 00^{\prime \prime} \mathrm{E}\right)$, Sichuan province, China [2], there are 44 rock flowslides that occurred in the mountainous area and consisted of the sand-mudstone mainly. The accumulation area is relatively flat though it is hard to compare with flowslides that occurred in Jingyang and coast of northern Europe. An important reason why the above three flowslide groups are taken as research objects is that they have similar flow characteristic and long runout distance. In addition, the topographical condition of the accumulation area is similar to the model test conditions. It can be seen from Figure 14 that the overall relationship between the apparent friction coefficient of flowslide and the slope angles shows a nonlinear growth relationship. This conclusion is consistent with Crosta [22]. The growth relationship is as follows:

$$
\frac{H}{L}=\frac{\tan \theta}{1+\left[(\cos \theta+\varepsilon \sin \theta)^{2} \cdot((\tan \theta / \mu)-1)\right]},
$$

where $\theta$ represents the slope angle; $H$ represents the slope height; $L$ represents the moving distance of the flowslide; $\varepsilon$ is the coefficient of velocity restitution when the sliding body reaches the slope break to change its moving direction to horizontal; $\mu$ is the friction coefficient.

The difference in regional lithology determines the difference between the friction coefficient $\mu$ and the coefficient of velocity restitution $\varepsilon$, so two different $\mu$ values and three different $\varepsilon$ values are set in this paper. When $\mu$ is 0.2 and $\varepsilon$ is $0,0.2$, or 0.4 , the curve better reflects the overall trend of the three natural flowslide groups. When the friction coefficient, $\mu$, between the inclined plate and the experimental material is 0.55 and $\varepsilon$ is 0.4 , the curve shows good correlation with the experimental points. It can be said that the friction coefficient determines the height of the initial benchmark of the curve. The larger the value of the friction coefficient, the higher the initial

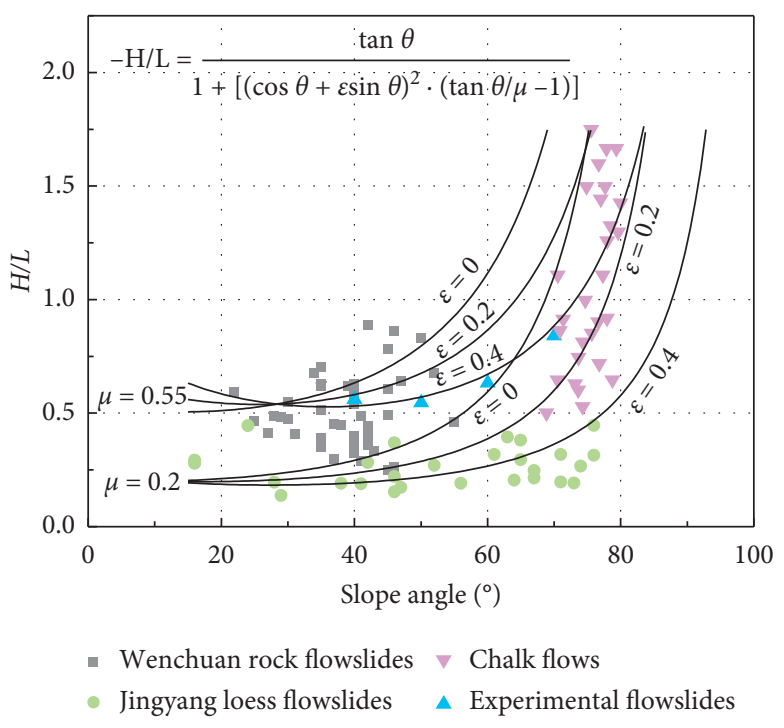

Figure 14: Comprehensive relationship between slope angle and apparent friction coefficient. Formula comes from Crosta [22].

benchmark of the curve. The coefficient of velocity restitution determines the change of the inflection point when the curve changes from flat to rapid. The larger the value of the coefficient of velocity restitution, the larger the horizontal coordinates of the inflection point.

From the point of energy conversion, energy loss at the slope break is closely related to terrain and lithology. The kinetic energy loss is small when the junction of slope and the accumulation area is a curved slope break; when the junction has sharp edges, the kinetic energy loss is larger $[13,22]$. Under the experimental conditions, in which slope height $H$ and volume are constant, as the slope angle increases, energy loss also increases due to the collision of the flowslide and the horizontal plate at the slope break $[43,44]$, which results in shorter distance of movement of the sliding body. The slope angle in the chalk flow area is too large, and the energy loss is excessive though the sliding path is lubricated by water beneath the accumulation area $1-2 \mathrm{~m}$. The flowslides in Wenchuan affected by lubrication due to water are few. Besides, there are many obstacles in the movement path because these flowslides are located in a mountainous area though the accumulation area is relatively flat, so energy loss is large. However, for the flowslides in Jingyang, the path is flat and straight as well as lubricated by the liquefied effect [31], and the energy loss is small. The flowslides in the model experiment fall between the three natural flowslide groups, to the left of chalk flows, above loess flowslides, and intersecting with rock flowslides. The apparent friction coefficient in the condition of this model experiment is not the smallest although the condition is ideal flat, for the reason that there are no lubrications. Therefore, the lubrication effect plays a key role in affecting the apparent friction coefficient.

\section{Discussion}

In this paper, the Taguchi method was employed innovatively to study quantitatively the order of significance 
and the maximal responses of combinations of factors affecting flowslide deposit morphology. The calculation results in Figure 5 confirm that slope angle is the most influential factor. The maximum influencing combination is a volume of $5.4 \times 10^{-3} \mathrm{~m}^{3}$, at a slope angle of $70^{\circ}$, and a slope height of $0.90 \mathrm{~m}$, which will be useful to evaluate the hazards of potential flowslides. Based on the accepted knowledge that slope angle is the largest influencing factor, further experimental research was performed. The conditions of small slope angles and large slope angles show interesting phenomena of single upheaval and double upheaval, respectively; the Mohr-Coulomb criterion is used to explain the action of the shear motion during the process. The comprehensive study of apparent friction coefficient shows a nonlinear increase with slope angle as well as spatial and lithological differences in distribution, which are affected by the friction coefficient and the coefficient of velocity restitution.

Similar model experiments have been carried out to analyze the movement rule of flowslide $[4,12,21]$ and deposit morphology [3, 16, 18, 22, 25]. Previous studies focused on the influence of a single factor, and the research content is more in-depth $[8,11,45,46]$, but the research process is not systematic enough, as flowslide movement and deposit morphology are determined by multiple factors, including volume, slope angle, slope height, sliding body material, and slip bed material. Of course, some scholars have conducted multifactor experiments; for example, Manzella [13] studied the influence of flowslide volume, initial height, slope of slip bed, and the slope break on movement characteristics, but the relative significance of various factors governing the movement of flowslide has not been revealed although the factors considered are comprehensive. An orthogonal experiment was used to study the motion characteristics (velocity, acceleration) of flowslide under the influence of various factors and found that slope angle was the largest influencing factor [33], which is consistent with the findings of this article though the research content was different.

The morphology of the double upheaval of flowslide was also observed in an experiment similar to the current study [1], which examined wave propagation in the macroscopic view. That experiment was also carried out with bulk materials. A wave would be formed when the experimental materials slid or fell into the accumulation area; the initial wave would accelerate suddenly as it was pushed by a subsequent wave propagating forward. The wave crest formed when motion stopped due to resistance may be one of the reasons for the formation of upheaval, and the wave trough can be regarded as wash [1] in this paper. According to the motion rule of the object, the flowslide is partially reflected at the slope break [22] and then propagates in the form of waves, which were observed somewhat during the experiment of larger slope angles. Macroscopic wave propagation may be the cause of the formation of upheaval and wash on the surface of flowslide, but if the phenomenon is deeply understood from the interior of sliding body, the internal shear behavior in the movement of flowslide may be reasonable. In addition, the morphology of actual flowslides is also affected by properties of sliding materials [14, 19, 20]. With an increase of the mass of fine particles, the length and width of the flowslide deposit increase first and then decrease [14]. Therefore, the difference of properties of granular materials is contributing to the formation of the double upheaval.

The apparent friction coefficient is often involved in the study of flowslide, but the focus here is on its relationship with volume $[5,7,9,21,38]$. There are few studies that use slope angle as a variable, including Lied and Bakkehoi [47] and Okura [3], both of which proposed that the apparent friction coefficient of flowslide was directly proportional to the slope angle, but the results were based on the analysis of only about 20 flowslides, so the conclusion was limited. The analysis in this paper involved 99 landslides in three areas, and the conclusion is consistent with the viewpoint of Crosta [22] in finding that the apparent friction coefficient increases nonlinearly as the slope angle increases. In the comparison made in this study, spatial and lithological differences in the apparent friction coefficient are also found.

In this paper, an experimental idea of constant height of the center of gravity is provided, but when the angle changes, the sliding distance of the flowslide on the inclined plate (Figure 4(b)) will inevitably increase, and the loss of kinetic energy due to friction will increase accordingly. Therefore, further improvement of the experimental device is needed to reduce the kinetic energy loss due to the increase in the sliding distance on the inclined plate. Modeling should also include more influencing factors.

\section{Conclusions}

(1) The combined influence factor obtained by the Taguchi method demonstrates that when flowslide volume is $5.4 \times 10^{-3} \mathrm{~m}^{3}$, the slope angle is $70^{\circ}$, the slope height is $0.90 \mathrm{~m}$, and the changes of deposit morphology of the flowslide is the largest. The extreme differences of maximum length $\left(L_{d}\right)$, maximum thickness $\left(D_{d}\right)$, area $(A)$, and the length-width ratio $\left(L_{d} / W_{d}\right)$ at three different levels under various factors are $2.77,5.51,4.54$, and 1.7 , respectively. The calculation results indicate that the factor that has the greatest impact on the deposit morphology of flowslide is slope angle, followed by volume and slope height.

(2) With an increase in slope angle, the width, length, area, and length-width ratio of flowslide deposits first increase and then decrease, and the maximum accumulation thickness first decreases and then increases. And, there should be a critical angle in the change laws of the flowslide deposit morphology, that is, between $60^{\circ}$ and $70^{\circ}$ under the experimental conditions. When the volume is $3.6 \times 10^{-3} \mathrm{~m}^{3}$ and the slope height is $0.90 \mathrm{~m}$, the slope angles at $40^{\circ}$ and $50^{\circ}$ both result in a single upheaval, while slope angles of $60^{\circ}$ and $70^{\circ}$ both result in a double upheaval, which has been explained by shear behavior in the sliding body based on the Mohr-Coulomb criterion. 
(3) The apparent friction coefficient of flowslide increases nonlinearly as the slope angle increases and shows spatial and lithological difference. The greater the friction coefficient of the sliding material, the higher the initial benchmark of the curve; the larger the coefficient of velocity restitution, the larger the abscissa corresponding to the position of inflection point when the curve changes from flat to rapid.

\section{Data Availability}

The data used to support the findings of this study are available from the corresponding author upon request.

\section{Conflicts of Interest}

The authors declare that they have no conflicts of interest.

\section{Acknowledgments}

This study would not have been possible without financial support from the Special Fund for the National Natural Science Foundation of China under Grant nos. 41702298, 41790442, and 41602359, as well as the Project Supported by Natural Science Basic Research Plan in Shaanxi Province of China under Grant no. 2017JQ4020.

\section{Supplementary Materials}

In this section, the data on the slope angles and the apparent friction coefficients are provided as a formation of table. These data are related to 44 rock flowslides in the Wenchuan, Sichuan province, China, 28 soil flowslides in in the Jingyang South platform, Shaanxi province, China, and 27 chalk flowslides along the coast of northern Europe. (Supplementary Materials)

\section{References}

[1] O. Roche, M. Attali, A. Mangeney, and A. Lucas, "On the runout distance of geophysical gravitational flows: insight from fluidized granular collapse experiments," Earth Planetary Science Letters, vol. 311, no. 3-4, pp. 375-385, 2011.

[2] D. Guo, M. Hamada, C. He, Y. Wang, and Y. Zou, "An empirical model for landslide travel distance prediction in Wenchuan earthquake area," Landslides, vol. 11, no. 2, pp. 281-291, 2014.

[3] Y. Okura, H. Kitahara, A. Kawanami, and U. Kurokawa, "Topography and volume effects on travel distance of surface failure," Engineering Geology, vol. 67, no. 3-4, pp. 243-254, 2003.

[4] Z. Han, Y. Li, J. Huang et al., "Numerical simulation for runout extent of debris flows using an improved cellular automaton model," Bulletin of Engineering Geology and the Environment, vol. 76, no. 3, pp. 961-974, 2017.

[5] F. Guzzeti, F. Ardizzone, M. Cardinali, M. Rossi, and D. Valigi, "Landslide volumes and landslide mobilization rates in Umbria, Central Italy," Earth Planetary Science Letters, vol. 279, no. 3-4, pp. 222-229, 2009.

[6] J. D. Chaytor, S. Uri, A. R. Solow, and B. Andrews, "Size distribution of submarine landslides along the US Atlantic margin," Marine Geology, vol. 264, no. 1-2, pp. 16-27, 2009.
[7] H. Qiu, P. Cui, A. D. Regmi et al., "Influence of topography and volume on mobility of loess slides within different slip surfaces," Catena, vol. 157, pp. 180-188, 2017.

[8] J. Hu, J. Peng, G. Wang, I. Javed, Y. Wang, and W. Li, "Distribution and characteristics of landslide in Loess Plateau: a case study in Shaanxi province," Engineering Geology, vol. 236, pp. 89-96, 2018.

[9] L. Xu, F. C. Dai, Q. M. Gong, L. G. Tham, and H. Min, "Irrigation-induced loess flow failure in Heifangtai Platform, north-west China," Environmental Earth Sciences, vol. 66, no. 6, pp. 1707-1713, 2012

[10] R. Q. Huang, W. H. Liu, J. P. Zhou, and X. J. Pei, "Rolling tests on movement characteristics of rock blocks," Journal of Geotechnical Engineering, vol. 29, no. 9, pp. 1296-1302, 2007, in Chinese.

[11] I. Manzella and V. Labiouse, "Physical modelling to better understand rock avalanches," in Physical Modelling in Geotechnics, Two Volume Set: Proceedings of the $7^{\text {th }}$ International Conference on Physical Modelling in Geotechnics (ICPMG 2010), vol. 2, pp. 1259-1265, Taylor \& Francis Group, London, UK, 2010.

[12] G. B. Crosta, F. V. De Blasio, M. De Caro, G. Volpi, S. Imposimato, and D. Roddeman, "Modes of propagation and deposition of granular flows onto an erodible substrate: experimental, analytical, and numerical study," Landslides, vol. 14, no. 1, pp. 47-68, 2017.

[13] I. Manzella and V. Labiouse, "Empirical and analytical analyses of laboratory granular flows to investigate rock avalanche propagation," Landslides, vol. 10, no. 1, pp. 23-36, 2013.

[14] Y.-X. Hu, H.-B. Li, S.-C. Qi, G. Fan, and J.-W. Zhou, "Granular effects on depositional processes of debris avalanches," KSCE Journal of Civil Engineering, vol. 24, no. 4, pp. 1116-1127, 2020.

[15] I. Goktepeli, U. Atmaca, and A. Cakan, "Investigation of heat transfer augmentation between the ribbed plates via Taguchi approach and computational fluid dynamics," Journal of Thermal Science, vol. 29, no. 3, pp. 647-666, 2020.

[16] M. Farin, A. Mangeney, and O. Roche, "Fundamental changes of granular flow dynamics, deposition, and erosion processes at high slope angles: insights from laboratory experiments," Journal of Geophysical Research: Earth Surface, vol. 119, no. 3, pp. 504-532, 2014.

[17] M. Kesseler, V. Heller, and B. Turnbull, "A laboratory-numerical approach for modelling scale effects in dry granular slides," Landslides, vol. 15, no. 11, pp. 2145-2159, 2018.

[18] A. Dufresne and T. R. Davies, "Longitudinal ridges in mass movement deposits," Geomorphology, vol. 105, no. 3-4, pp. 171-181, 2009.

[19] T. De Haas, L. Braat, J. R. F. W. Leuven, I. R. Lokhorst, and M. G. Kleinhans, "Effects of debris flow composition on runout, depositional mechanisms, and deposit morphology in laboratory experiments," Journal of Geophysical Research: Earth Surface, vol. 120, no. 9, pp. 1949-1972, 2015.

[20] C. Goujon, N. Thomas, and B. Dalloz-Dubrujeaud, "Monodisperse dry granular flows on inclined planes: role of roughness," The European Physical Journal E, vol. 11, no. 2, pp. 147-157, 2003.

[21] X.-Y. Fan, S.-J. Tian, and Y.-Y. Zhang, "Mass-front velocity of dry granular flows influenced by the angle of the slope to the runout plane and particle size gradation," Journal of Mountain Science, vol. 13, no. 2, pp. 234-245, 2016.

[22] G. B. Crosta, F. V. D. Blasio, M. Locatelli, S. Imposimato, and D. Roddeman, "Landslides falling onto a shallow erodible 
substrate or water layer: an experimental and numerical approach," IOP Conference Series: Earth and Environmental Science, vol. 26, no. 1, Article ID 012004, 2015.

[23] C. Quantin, P. Allemand, and C. Delacourt, "Morphology and geometry of valles marineris landslides," Planetary and Space Science, vol. 52, no. 11, pp. 1011-1022, 2004.

[24] B. K. Lucchitta, "Landslides in valles marineris, mars," Journal of Geophysical Research, vol. 84, no. B14, pp. 8097-8113, 1979.

[25] B. K. Lucchitta, "Morphology of chasma walls, Mars," Journal of Research of the U.S. Geological Survey, vol. 6, no. 5, pp. 651-662, 1978.

[26] J. J. Wu, Z. W. Xie, Y. L. Huang, and X. M. Wu, "Sensitivity analysis on stress of flexible hinges to design parameters based on Taguchi method," Journal of Mechanical Strength, vol. 38, no. 2, pp. 252-258, 2016.

[27] S. D. Kumar, P. R. Vundavilli, A. Mandal, S. Mantry, and M. Chakraborty, "Erosion response of thixoformed A3565TiB2 in situ composite using Taguchi's experimental design," Tribology Transactions, vol. 60, no. 1, pp. 39-46, 2017.

[28] M. Bagci and H. Imrek, "Application of Taguchi method on optimization of testing parameters for erosion of glass fiber reinforced epoxy composite materials," Materials \& Design, vol. 46, pp. 706-712, 2013.

[29] M. Bagci and H. Imrek, "Erosion wear performance of borax filled novel hybrid composites by using the Taguchi experimental design," Industrial Lubrication and Tribology, vol. 68, no. 1, pp. 134-140, 2016.

[30] Z. Duan, W.-C. Cheng, J.-B. Peng, Q.-Y. Wang, and W. Chen, "Investigation into the triggering mechanism of loess landslides in the south Jingyang platform, Shaanxi province," Bulletin of Engineering Geology and the Environment, vol. 78, no. 7, pp. 4919-4930, 2019.

[31] P. Ma, J. Peng, Q. Wang, Z. Duan, Z. Meng, and Z. Jianqi, "Loess landslides on the South Jingyang platform in Shaanxi province, China," Quarterly Journal of Engineering Geology and Hydrogeology, vol. 52, no. 4, pp. 547-556, 2019.

[32] P. Asteriou, H. Saroglou, and G. Tsiambaos, "Geotechnical and kinematic parameters affecting the coefficients of restitution for rock fall analysis," International Journal of Rock Mechanics and Mining Sciences, vol. 54, pp. 103-113, 2012.

[33] R. Q. Huang and W. H. Liu, "In-situ test study of characteristics of rolling rock blocks based on orthogonal design," Chinese Journal of Rock Mechanics Engineering Geology, vol. 28, no. 5, pp. 882-891, 2009, in Chinese.

[34] L.-T. Zhan, Z. Zhang, Y.-M. Chen et al., "The 2015 Shenzhen catastrophic landslide in a construction waste dump: reconstitution of dump structure and failure mechanisms via geotechnical investigations," Engineering Geology, vol. 238, pp. 15-26, 2018.

[35] C. S. Chen, Q. Q. Li, J. S. Zhu et al., "Formation of the 2015 Shenzhen landslide as observed by SAR shape-from-shading," Scientific Reports, vol. 7, no. 1, Article ID 43351, 2017.

[36] J. N. Hutchinson, S. G. Evans, and J. V. Degraff, "Chalk flows from the coastal cliffs of Northwest Europe," in Catastrophic Landslides, vol. 15, pp. 257-302, Geological Society of America, Boulder, Colo, USA, 2002.

[37] A. Hénaff, Y. Lageat, S. Costa, and E. Plessis, "Le recul des falaises crayeuses du Pays de Caux:détermination des processus d'érosion et quantification des rythmes d'évolution/ Retreat of chalk cliffs in the Pays de Caux: processes and rates," Géomorphologie: Relief, Processus, Environnement, vol. 8, no. 2, pp. 107-118, 2002.

[38] A. Lucas, A. Mangeney, and J. P. Ampuero, "Frictional velocity-weakening in landslides on earth and on other planetary bodies," Nature Communications, vol. 5, no. 1, pp. 1-9, 2014.

[39] A. N. Edwards and J. M. N. T. Gray, "Erosion-deposition waves in shallow granular free-surface flows," Journal of Fluid Mechanics, vol. 762, pp. 35-67, 2015.

[40] E. D. Fern' andez-Nieto, J. Garres-D'1az, A. Mangeney, and G. Narbona-Reina, "A multilayer shallow model for dry granular flows with the $\mu$ (I) rheology: application to granular collapse on erodible beds," Journal of Fluid Mechanics, vol. 798, pp. 643-681, 2015.

[41] J.-J. Wang, H.-P. Zhang, S.-C. Tang, and Y. Liang, "Effects of particle size distribution on shear strength of accumulation soil," Journal of Geotechnical and Geoenvironmental Engineering, vol. 139, no. 11, pp. 1994-1997, 2013.

[42] L. J. Su, W. H. Zhou, W. B. Chen, and X. Jie, "Effects of relative roughness and mean particle size on the shear strength of sand-steel interface," Measurement, vol. 122, pp. 330-346, 2018.

[43] L.-P. Li, S.-Q. Sun, S.-C. Li, Q.-Q. Zhang, C. Hu, and S.-S. Shi, "Coefficient of restitution and kinetic energy loss of rockfall impacts," KSCE Journal of Civil Engineering, vol. 20, no. 6, pp. 2297-2307, 2015.

[44] K. Sharma, S. S. Mallick, and A. Mittal, "A study of energy loss due to particle to particle and wall collisions during fluidized dense-phase pneumatic transport," Powder Technology, vol. 362, pp. 707-716, 2020.

[45] H. Qiu, A. D. Regmi, P. Cui, S. Hu, Y. Wang, and Y. He, "Slope aspect effects of loess slides and its spatial differentiation in different geomorphologic types," Arabian Journal of Geosciences, vol. 10, no. 15, p. 344, 2017.

[46] C. M. Lo, M. L. Lin, C. L. Tang, and J. C. Hu, “A kinematic model of the Hsiaolin landslide calibrated to the morphology of the landslide deposit," Engineering Geology, vol. 123, no. 12, pp. 22-39, 2011.

[47] K. Lied and K. Bakkehøi, "Empirical calculations of snowavalanche run-out distance based on topographic parameters," Journal of Glaciology, vol. 26, no. 94, pp. 165-177, 1980. 